\title{
LUNG STIFFNESS IN STATES OF ABNORMAL PULMONARY BLOOD FLOW AND PRESSURE
}

\author{
BY \\ HYWEL DAVIES, JOHN WILLIAMS, AND PAUL WOOD \\ From the National Heart Hospital and the Brompton Hospital, London \\ Received August 21, 1961
}

The suspicion that pulmonary function in general and pulmonary compliance in particular might be disturbed by hyperkinetic pulmonary hypertension (increased pulmonary flow in the presence of increased pulmonary arterial pressure) arose from a study of the incidence of chest deformities in congenital heart disease (Davies, 1959). It was then observed that hyperkinetic pulmonary hypertension was often associated with a bilaterally increased antero-posterior chest diameter, sternal protrusion, and indrawing of the lower ribs on inspiration. Since hyperkinetic pulmonary hypertension occurs most commonly with ventricular septal defect, it is in conjunction with this lesion that such a deformity is usually seen (Fig. 1), although it occurs with other anomalies that disturb the pulmonary circulation in similar fashion (Fig. 2). In uncomplicated atrial septal defect of the secundum variety and in the Eisenmenger situation this type of chest deformity is rarely seen (Fig. 3). It was suggested that the abnormal shape of the chest might be due to altered pulmonary mechanics related to a combination of high pressure and high flow, but not to one or the other of these factors independently.

Since increased stiffness of the lung seemed the most likely disturbance of pulmonary mechanics to cause a thoracic deformity of the kind described, we measured the pulmonary compliance in 34 patients with congenital heart disease causing high pressure, high flow, or both.
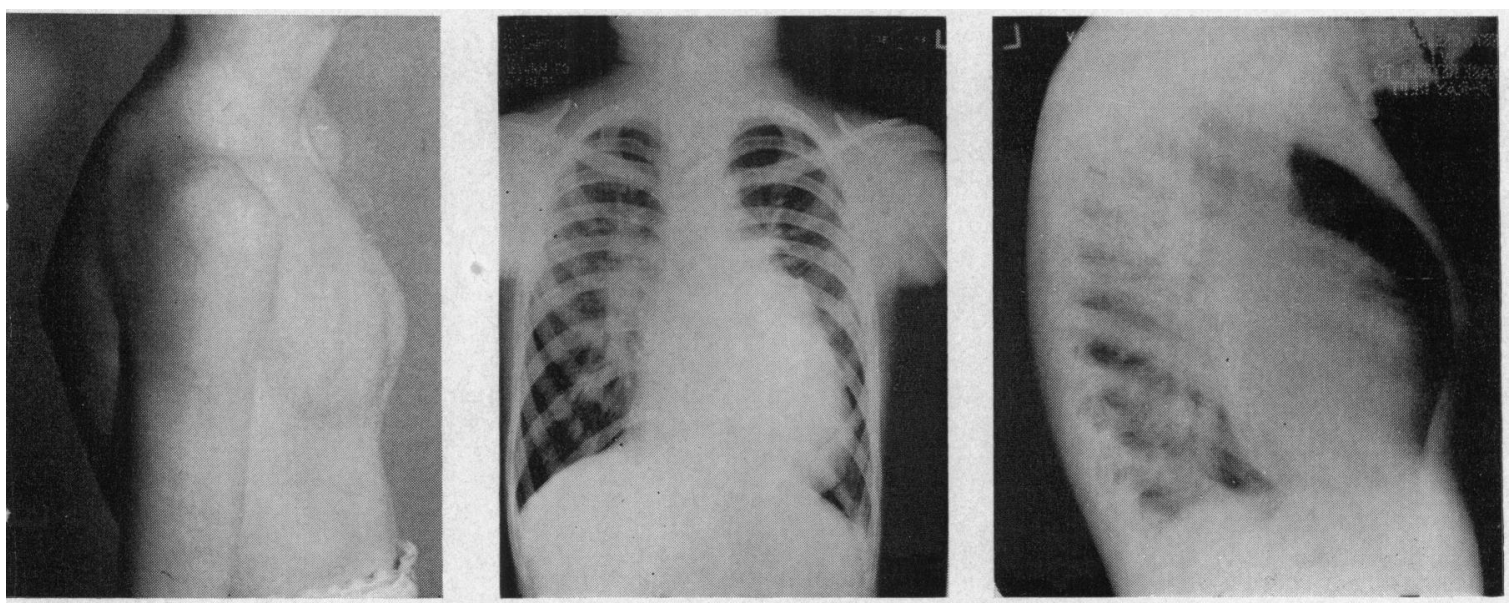

FIG. 1.-A patient aged 13 (Case 4) with ventricular septal defect, corrected transposition and hyperkinetic pulmonary hypertension. The bilateral chest deformity is seen in the photograph. The lateral chest X-ray shows a clear area between the heart and sternum, indicating that the deformity was not caused by pressure of the enlarged heart on the chest wall. 

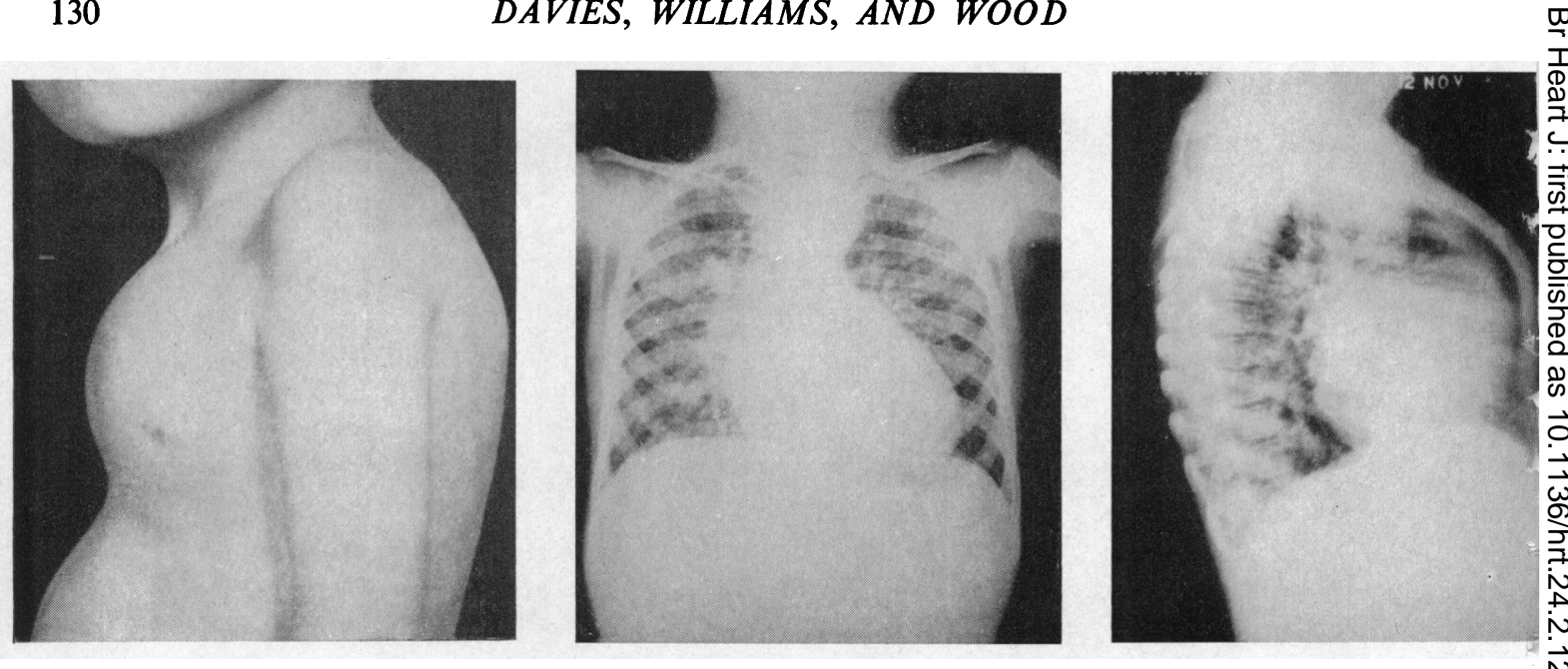

Fig. 2.-A patient aged four with complete transposition of the great vessels and hyperkinetic pulmonary hypertension.

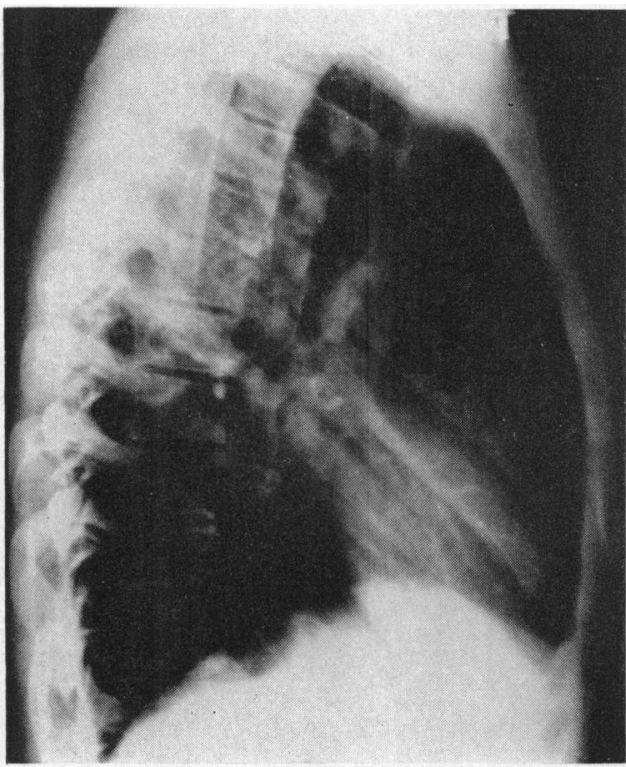

(A)

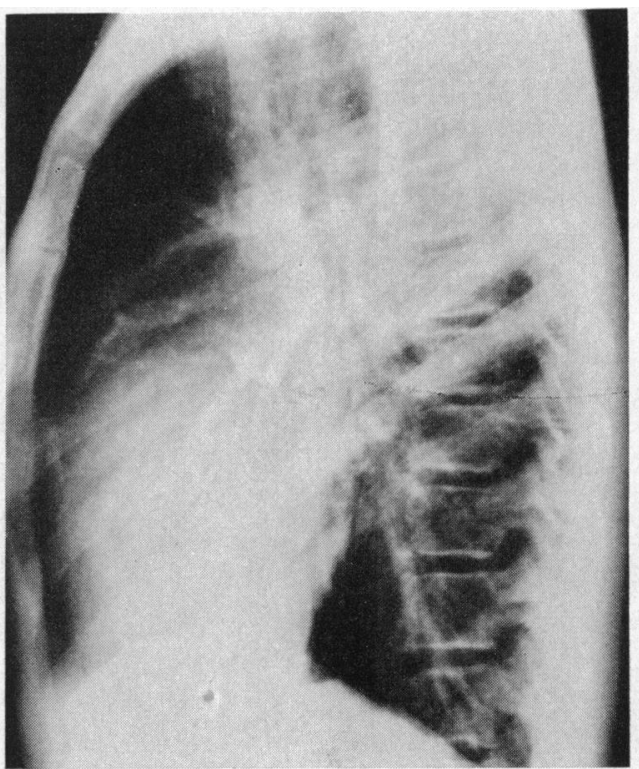

(B)

Fig. 3.-Normal configuration of chest as seen in lateral X-rays of patients with (A) atrial septal defect, (B) Eisenmenger complex.

\section{METHOD AND MATERIALS}

Static lung compliance and lung volumes were estimated in 20 patients with ventricular septal defect, 13 patients with atrial septal defect and one with a patent ductus arteriosus and pulmonary hypertension. The results of cardiac catheterization were available in all but two; in one of these the findings at surgery were known subsequently. 
Lung compliance was measured by recording simultaneously the tidal volume and the osophageal pressure (Frank et al., 1956). A latex balloon connected to one side of a differential manometer by polythene tubing was passed into the middle of the œsophagus under local anæsthesia. The other side of the manometer was connected to a spirometer, the net reading representing the difference between œsophageal and mouth pressure. This was recorded throughout the phases of respiration by means of a cathode ray oscillograph. The corresponding changes in lung volume were registered on the same tracing, with the aid of a rotary wirewound linear potentiometer attached to the spirometer. The static lung compliance was calculated in litres per $\mathrm{cm}$. water pressure, as the ratio of volume change to pressure change between the points of no flow. The mean of 10 respresentative tracings was taken with the patient breathing slowly. Lung volumes were measured by the closedcircuit helium dilution method of McMichael (1939). The patient's surface area in square metres was measured from a nomogram based on the formula of Dubois and Dubois (1915).

There was considerable variation in the ages and sizes of the patients studied. Lung compliance varies directly with lung volume: a small lung has a lower compliance (greater stiffness) than a large one of identical structure, since for a given pressure change the amount of air entering an infant's lung would be much smaller than in an adult's. Marshall (1957) showed that the following relationship exists.

Lung compliance (litres $/ \mathrm{cm}$. water) $=0.05 \times$ Functional Residual Capacity (FRC), where FRC is defined as the volume of air left in the lung after a quiet expiration. This relationship was deduced by Marshall after study of 50 normal patients (41 adults aged 19-35 and 5 children aged 9-12). The lowest FRC obtained was 0.87 litres, a figure similar to the lowest measured by us. The correlation coefficient for the relationship is 0.904 and the maximum and minimum values for the factors were 0.0702 and 0.0378 respectively. The ratio of lung compliance to FRC is thus more or less constant in normal people, and we determined to use this fact in correcting for the greatly differing sizes of the individuals in this study.

\section{RESULTS}

Patients with ventricular septal defects were divided into two groups.

Ventricular Septal Defect with Hyperkinetic Pulmonary Hypertension. Eight patients (Cases 1-8) had a pulmonary blood flow exceeding 6 litres/min./sq.m. body surface area, and a mean pulmonary arterial pressure above $25 \mathrm{~mm}$. $\mathrm{Hg}$. The pulmonary compliance was abnormally low in five of them and just above the lower limit of normal in three (Cases 4, 6, and 8).

Ventricular Septal Defects without Hyperkinetic Pulmonary Hypertension. There were twelve patients in this group. Eleven had increased pulmonary blood flow but low pressure (Cases 10-20), while one had increased pressure but low flow (Case 9). All twelve patients had normal or high compliance.

Details of Cases 1-20 are given in Table I and Fig. 4.

Atrial Septal Defect. There were 13 patients in this group. Seven had straight-forward secundum-type defects (Cases 21-27). In two of these the compliance was near the lower limit of normal (Cases 23 and 24), while in the remainder it was normal or high. Two patients had total anomalous pulmonary venous drainage (Cases 30 and 31): the compliance was normal in one of them and just above the lower limit of normal in the other. Two had an ostium primum type lesion (Cases 28 and 29): compliance was normal in one and at the lower limit of normal in the other. One patient had severe pulmonary hypertension (Eisenmenger reaction) present from an early age (Case 33): her compliance was normal $(0 \cdot 11)$. One had pulmonary hypertension which was thought to have been acquired during the course of the disease (Case 32): her compliance was low $(0 \cdot 04)$. Details are given in Table II and Fig. 5. 
TABLE I

Results in Ventricular Septal Defect

\begin{tabular}{|c|c|c|c|c|c|c|c|c|c|}
\hline $\begin{array}{c}\text { Case } \\
\text { Number }\end{array}$ & Age & Sex & $\begin{array}{l}\text { P.F. } \\
\text { (litre) }\end{array}$ & P.F./S.A. & $\begin{array}{l}\text { Mean } \\
\text { P.A.P. } \\
\text { (mm.) }\end{array}$ & P.F./S.F. & $\underset{\text { (litre) }}{\text { F.R.C. }}$ & $\begin{array}{c}\text { Compliance } \\
\text { (litre } / \mathrm{cm} \text {.) }\end{array}$ & $\frac{\text { Compliance }}{\text { F.R.C. }}$ \\
\hline $\begin{array}{l}1 \\
2 \\
3 \\
4 \\
5 \\
6 \\
7 \\
8\end{array}$ & $\begin{array}{r}19 \\
7 \\
7 \\
13 \\
17 \\
6 \\
6 \\
6\end{array}$ & $\begin{array}{l}M \\
M \\
M \\
M \\
F \\
M \\
M \\
F\end{array}$ & $\begin{array}{r}21 \cdot 4 \\
6 \cdot 3 \\
8 \cdot 7 \\
9 \cdot 3 \\
12 \cdot 0 \\
5 \cdot 0 \\
13 \cdot 0 \\
12 \cdot 3\end{array}$ & $\begin{array}{r}12.9 \\
10.0 \\
11.4 \\
7.0 \\
9.0 \\
6.2 \\
16.0 \\
14.8\end{array}$ & $\begin{array}{l}65 \\
75 \\
47 \\
37 \\
75 \\
50 \\
52 \\
27\end{array}$ & $\begin{array}{l}3 \cdot 8 \\
1 \cdot 8 \\
2 \cdot 7 \\
2 \cdot 1 \\
2 \cdot 3 \\
1 \cdot 7 \\
2 \cdot 6 \\
2 \cdot 4\end{array}$ & $\begin{array}{l}3 \cdot 6 \\
1 \cdot 3 \\
0.9 \\
1.4 \\
1.9 \\
1 \cdot 3 \\
1.0 \\
1 \cdot 3\end{array}$ & $\begin{array}{l}0.085 \\
0.030 \\
0.023 \\
0.064 \\
0.038 \\
0.058 \\
0.034 \\
0.053\end{array}$ & $\begin{array}{l}0.023 \\
0.024 \\
0.026 \\
0.046 \\
0.020 \\
0.043 \\
0.034 \\
0.040\end{array}$ \\
\hline $\begin{array}{r}9 \\
10 \\
11 \\
12 \\
13 \\
14 \\
15 \\
16 \\
17 \\
18 \\
19^{*} \\
20^{*}\end{array}$ & $\begin{array}{r}17 \\
12 \\
14 \\
13 \\
16 \\
9 \\
6 \\
15 \\
12 \\
14 \\
56 \\
18\end{array}$ & $\begin{array}{l}M \\
M \\
F \\
M \\
M \\
M \\
F \\
M \\
F \\
M \\
F \\
F\end{array}$ & $\begin{array}{r}6 \cdot 5 \\
7 \cdot 6 \\
17 \cdot 6 \\
14 \cdot 0 \\
11 \cdot 0 \\
10 \cdot 1 \\
4 \cdot 8 \\
4 \cdot 7 \\
6 \cdot 0 \\
9 \cdot 0 \\
14 \cdot 8 \\
15 \cdot 5\end{array}$ & $\begin{array}{r}3.9 \\
6.0 \\
11.3 \\
9.4 \\
6.9 \\
9.3 \\
5.0 \\
3.0 \\
4.3 \\
6.5 \\
11.1 \\
10.2\end{array}$ & $\begin{array}{r}43 \\
11 \\
15 \\
11 \\
10 \\
15 \\
12 \\
9 \\
11 \\
10 \\
20 \\
15\end{array}$ & $\begin{array}{l}1 \cdot 9 \\
1 \cdot 5 \\
3 \cdot 1 \\
2 \cdot 2 \\
2 \cdot 4 \\
2 \cdot 5 \\
2 \cdot 6 \\
1 \cdot 4 \\
1 \cdot 2 \\
1 \cdot 2 \\
2 \cdot 8 \\
2 \cdot 0\end{array}$ & $\begin{array}{l}3 \cdot 7 \\
2 \cdot 8 \\
2 \cdot 4 \\
1 \cdot 8 \\
3 \cdot 1 \\
1 \cdot 9 \\
0 \cdot 9 \\
4 \cdot 0 \\
1 \cdot 9 \\
2 \cdot 3 \\
2 \cdot 4 \\
2 \cdot 9\end{array}$ & $\begin{array}{l}0 \cdot 210 \\
0 \cdot 250 \\
0 \cdot 095 \\
0 \cdot 10 \\
0 \cdot 20 \\
0.09 \\
0 \cdot 07 \\
0 \cdot 23 \\
0 \cdot 16 \\
0.09 \\
0 \cdot 15 \\
0 \cdot 14\end{array}$ & $\begin{array}{l}0.058 \\
0.088 \\
0.040 \\
0.056 \\
0.066 \\
0.049 \\
0.081 \\
0.058 \\
0.086 \\
0.041 \\
0.064 \\
0.049\end{array}$ \\
\hline
\end{tabular}

* V.S.D. and pulmonary stenosis

P.F. = Pulmonary flow (litre $/ \mathrm{min}$.)

S.A. $=$ Surface area (sq. m.).

P.A.P. $=$ Pulmonary artery pressure $(\mathrm{mm} . \mathrm{Hg})$

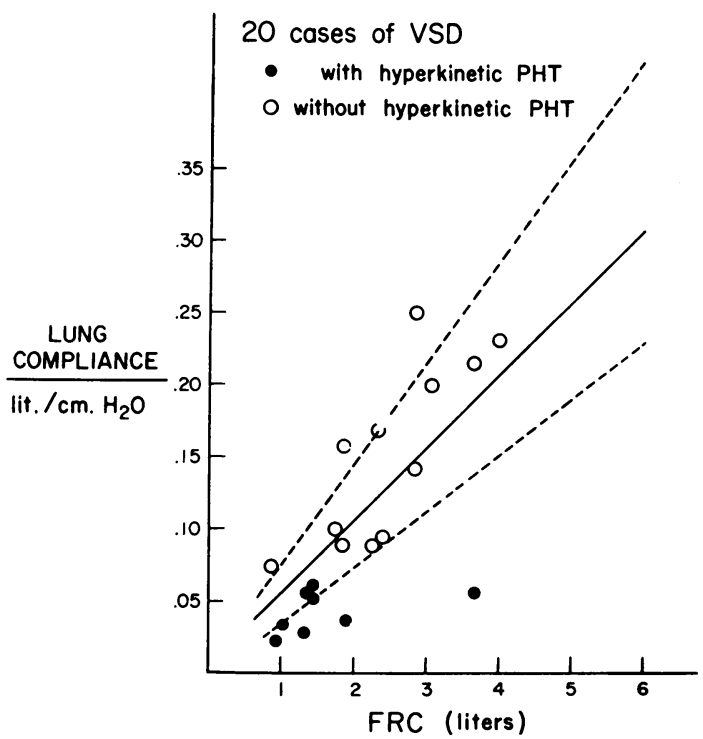

FIG. 4.-Lung compliance related to functional residual capacity (FRC) in 20 patients with V.S.D. The patients with hyperkinetic pulmonary hypertension show a reduced compliance. (Normal limits from Marshall, 1957).
S.F. $=$ Systemic flow

F.R.C. = Functional residual capacity (litre)

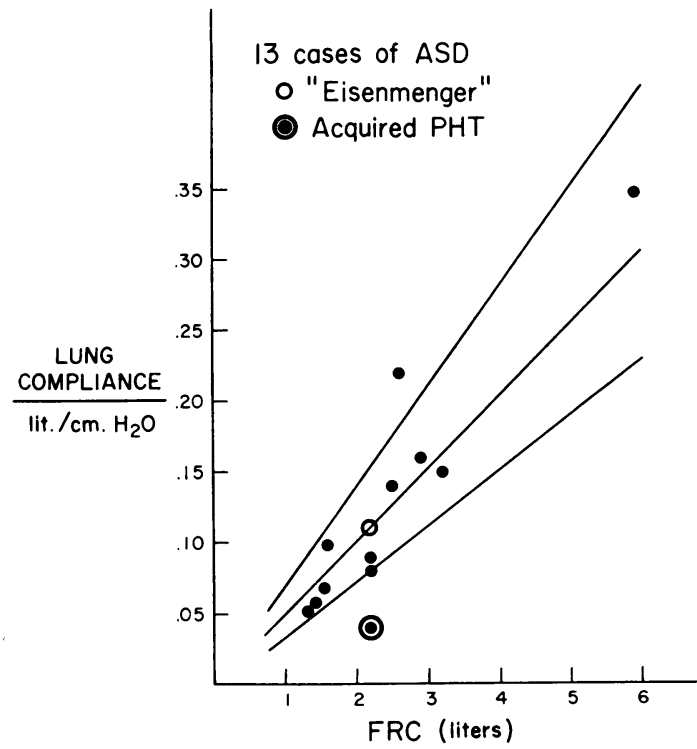

FIG. 5.- Lung compliance related to functional residual capacity (FRC) in 13 patients with A.S.D. All had a normal pulmonary artery pressure, except the two cases indicated. Of these two, one was considered to have had severe pulmonary hypertension from birth, and the other to have acquired it during the course of the disease. 
TABLE II

Data Obtained at Cardiac Catheterization and on Pulmonary Function Testing in 13 Cases with Atrial Septal Defect and one with Patent Ductus Arteriosus

\begin{tabular}{|c|c|c|c|c|c|c|c|c|c|c|}
\hline $\begin{array}{l}\text { Case } \\
\text { Number }\end{array}$ & Diagnosis & Age & Sex & $\begin{array}{c}\text { P.F. } \\
\text { (litre) }\end{array}$ & P.F./S.A. & $\begin{array}{l}\text { Mean } \\
\text { P.A.P. } \\
\text { (mm.) }\end{array}$ & P.F./S.F. & $\begin{array}{l}\text { F.R.C. } \\
\text { (litre) }\end{array}$ & $\begin{array}{c}\text { Compliance } \\
\text { (litre } / \mathrm{cm} .)\end{array}$ & $\frac{\text { Compliance }}{\text { F.R.C. }}$ \\
\hline $\begin{array}{l}21 \\
22 \\
23 \\
24 \\
25 \\
26 \\
27\end{array}$ & $\begin{array}{l}\text { A.S.D. } \\
\text { A.S.D. } \\
\text { A.S.D. } \\
\text { A.S.D. } \\
\text { A.S.D. } \\
\text { A.S.D. } \\
\text { A.S.D. }\end{array}$ & $\begin{array}{r}23 \\
12 \\
9 \\
9 \\
42 \\
23 \\
12\end{array}$ & $\begin{array}{l}\mathrm{M} \\
\mathrm{M} \\
\mathrm{M} \\
\mathrm{F} \\
\mathrm{F} \\
\mathrm{M} \\
\mathrm{F}\end{array}$ & $\begin{array}{c}16 \cdot 0 \\
31 \cdot 5 \\
8 \cdot 3 \\
\overline{9 \cdot 7} \\
13 \cdot 6\end{array}$ & $\begin{array}{c}8 \cdot 3 \\
23 \cdot 3 \\
7 \cdot 8 \\
\overline{5} \cdot 4 \\
\\
8 \cdot 0 \\
\text { h. } \quad \text { Large }\end{array}$ & $\begin{array}{c}10 \\
9 \\
10 \\
16 \\
19 \\
6 \\
\text { low at o }\end{array}$ & $\begin{array}{r}2 \cdot 3 \\
4 \cdot 2 \\
2 \cdot 3 \\
3 \cdot 8 \\
2 \cdot 0 \\
2 \cdot 4 \\
\text { eration }\end{array}$ & $\begin{array}{l}5 \cdot 9 \\
1 \cdot 6 \\
1 \cdot 3 \\
1 \cdot 4 \\
2 \cdot 6 \\
3 \cdot 2 \\
1 \cdot 5\end{array}$ & $\begin{array}{l}0 \cdot 349 \\
0 \cdot 096 \\
0 \cdot 051 \\
0.056 \\
0 \cdot 22 \\
0 \cdot 15 \\
0.069\end{array}$ & $\begin{array}{l}0.059 \\
0.060 \\
0.039 \\
0.040 \\
0.084 \\
0.046 \\
0.045\end{array}$ \\
\hline $\begin{array}{l}28 \\
29\end{array}$ & $\begin{array}{l}\text { A.S.D. } \\
\text { Prim. } \\
\text { A.S.D. } \\
\text { Prim. }\end{array}$ & $\begin{array}{l}19 \\
29\end{array}$ & $\begin{array}{l}M \\
M\end{array}$ & $\begin{array}{l}16 \cdot 0 \\
17 \cdot 5\end{array}$ & $\begin{array}{r}9 \cdot 9 \\
10 \cdot 5\end{array}$ & $\begin{array}{l}10 \\
11\end{array}$ & $\begin{array}{l}3 \cdot 2 \\
4 \cdot 4\end{array}$ & $\begin{array}{l}2 \cdot 9 \\
2 \cdot 2\end{array}$ & $\begin{array}{l}0 \cdot 16 \\
0.08\end{array}$ & $\begin{array}{l}0.054 \\
0.036\end{array}$ \\
\hline $\begin{array}{l}30 \\
31\end{array}$ & $\begin{array}{l}\text { A.S.D. } \\
\text { T.A.V.D. } \\
\text { A.S.D. } \\
\text { T.A.V.D. }\end{array}$ & $\begin{array}{l}15 \\
15\end{array}$ & $\begin{array}{l}M \\
M\end{array}$ & $\begin{array}{l}10 \cdot 8 \\
11 \cdot 0\end{array}$ & $\begin{array}{l}9 \cdot 2 \\
9 \cdot 0\end{array}$ & $\begin{array}{l}20 \\
21\end{array}$ & $\begin{array}{l}3 \cdot 3 \\
2 \cdot 1\end{array}$ & $\begin{array}{l}2 \cdot 5 \\
2 \cdot 2\end{array}$ & $\begin{array}{l}0 \cdot 14 \\
0 \cdot 088\end{array}$ & $\begin{array}{l}0.058 \\
0.040\end{array}$ \\
\hline 32 & $\begin{array}{l}\text { A.S.D. } \\
\text { P.H.T. }\end{array}$ & 52 & $\mathrm{~F}$ & $7 \cdot 1$ & $4 \cdot 6$ & 53 & $1 \cdot 7$ & $2 \cdot 2$ & 0.040 & 0.018 \\
\hline 33 & $\begin{array}{l}\text { A.S.D. } \\
\text { Eis. }\end{array}$ & 36 & $F$ & $5 \cdot 5$ & $3 \cdot 2$ & 50 & $1 \cdot 3$ & $2 \cdot 2$ & $0 \cdot 11$ & 0.050 \\
\hline 34 & $\begin{array}{l}\text { P.D.A. } \\
\text { Eis. }\end{array}$ & 19 & $\mathbf{M}$ & $7 \cdot 4$ & 4.9 & 98 & $2 \cdot 1$ & $3 \cdot 1$ & $0 \cdot 21$ & 0.069 \\
\hline $\begin{array}{r}\text { P. } \\
\text { S. } \\
\text { P.A. } \\
\text { S. } \\
\text { F.R. }\end{array}$ & $\begin{array}{l}\text { Pulmon } \\
\text { Surface } \\
\text { Pulmon } \\
\text { Systemi } \\
\text { Functio }\end{array}$ & arte & res & $\begin{array}{l}\text { (mm. H } \\
y \text { (litre) }\end{array}$ & & $\begin{array}{l}\text { Prim. }= \\
\text { V.D. }= \\
\text { H.T. }= \\
\text { Eis. }=\end{array}$ & $\begin{array}{l}\text { stium prir } \\
\text { tal anom } \\
\text { llmonary } \\
\text { senmenge }\end{array}$ & $\begin{array}{l}\text { n } \\
\text { us pu } \\
\text { oerten }\end{array}$ & $\begin{array}{l}\text { nonary venc } \\
\text { on }\end{array}$ & drainage \\
\hline
\end{tabular}

\section{ANALYSIS OF DATA}

A graph of compliance (litre/cm. water) divided by functional residual capacity (FRC, litres) plotted against the mean pulmonary arterial pressure for all cases with an increased pulmonary flow is given in Fig. 6. It shows that the compliance per unit lung volume falls as the pressure rises.

The compliance per unit lung volume against the pulmonary index (blood flow per square metre surface area) is expressed in Fig. 7. This suggests that compliance also tends to fall as the flow increases (apart from one outlying observation in a case of atrial septal defect in which a large pulmonary blood flow was associated with a relatively high compliance).

The value of compliance/FRC in the different groups studied is shown in Fig. 8. Group A consists of the 11 cases of ventricular septal defect without pulmonary hypertension (Case 9 in Table I had pulmonary hypertension with a normal pulmonary blood flow and has been assigned to Group D). Group B comprises the eight cases of hyperkinetic pulmonary hypertension. Group C shows the 12 cases of A.S.D., except Case 33 with the Eisenmenger reaction. One strikingly low value is seen. This was the patient aged 52 with pulmonary hypertension $(85 / 20)$ and moderate dyspnœa.* Her pulmonary: systemic flow ratio was 1.75. Group D consists of Case 23, an example of A.S.D. with the Eisenmenger reaction, and Case 9, mentioned above. The latter had pulmonary hyper-

* The difference in the values between Group A and Group B is statistically highly significant (p less than 0.001). That between Group C and Group B is significant ( $p$ less than 0.01 ). There is no significant difference between Groups A and C. 

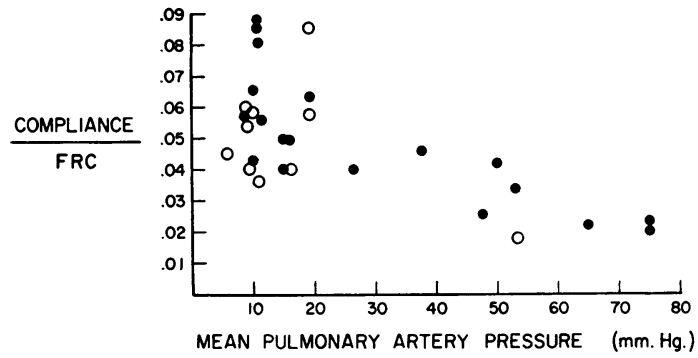

Fig. 6.-The compliance per unit lung volume related to the mean pulmonary artery pressure in all cases with an increased pulmonary blood flow, showing a fall in compliance as the pressure rises. (A.S.D. shown as open circles and V.S.D. as closed circles).

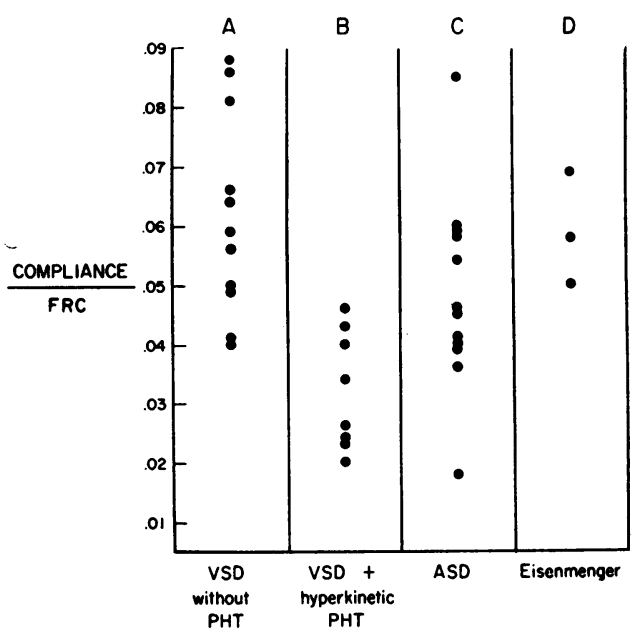

FIG. 8.-The compliance per unit lung volume in the four groups studied. Groups $A$ and D show normal values. Those of Group B are clearly low, whilst Group $\mathbf{C}$ shows a wide scatter(see text), the very low value representing the patient with acquired pulmonary hypertension.

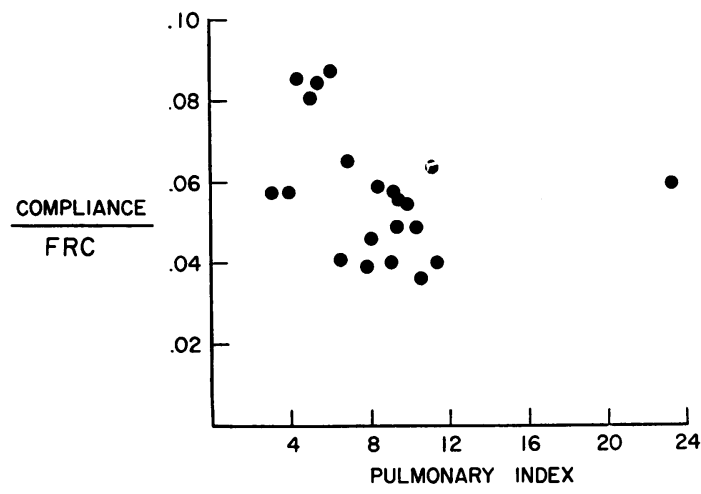

FIG. 7.-The compliance per unit lung volume related to the pulmonary index (pulmonary blood flow per square metre surface area) in cases with normal pulmonary artery pressure. There appears to be a tendency for the compliance to fall with increasing flow, though the patient with the largest flow showed normal compliance.

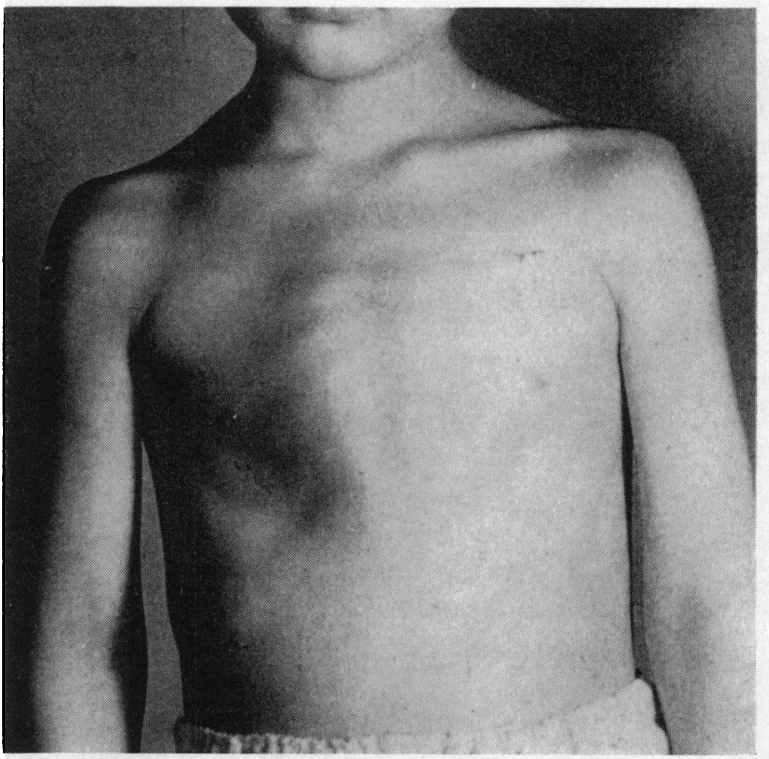

FIG. 9.-A boy aged 10 with cor triatriatum, showing the chest deformity under discussion.

tension with a normal pulmonary blood flow, despite a left-to-right shunt at ventricular level. The clinical picture was that of the Eisenmenger complex. To these has been added one further patient, not included in the previous figures. He was a young man of 19 years of age who, at the time of study, was thought to have the true Eisenmenger complex. Later, with further evidence, the diagnosis was changed to that of patent ductus arteriosus with the Eisenmenger reaction. He provides a good illustration of the co-existence of severe pulmonary hypertension (120/75) and a normal compliance $(0 \cdot 21)$. 


\section{Discussion}

There has been considerable divergence of opinion about the relationship between altered pulmonary hæmodynamics and the mechanical properties of the lungs. Most authors agree that pulmonary hypertension is associated usually with some degree of increased lung stiffness (Pryor et al., 1955; Mcllroy and Apthorp, 1958) though there is no consistent quantitative relationship between the two (Saxton et al., 1956). During the course of this study we measured the compliance of two subjects with severe pulmonary hypertension. The first was aged 36, with an atrial septal defect and the second aged 19, with a patent ductus arteriosus (Cases 33 and 34). The compliances were respectively $0 \cdot 110$ and $0 \cdot 214$ litre $/ \mathrm{cm}$. water. It is clear from this, as well as from the findings in several of our cases of primary or thrombo-embolic pulmonary hypertension and from other published data, that severe pulmonary hypertension and a normal lung compliance are not incompatible. It would appear that increased lung stiffness associated with severe pulmonary hypertension is caused by secondary or parallel changes in the lung parenchyma, and not by the hypertension ipso facto. Thus in primary and chronic thrombo-embolic pulmonary hypertension it is a relatively late manifestation and certainly does not explain the hyperventilation so characteristic of these two conditions. Dyspnœea in the early stages of the Eisenmenger syndrome is clearly hypoxic, for it does not occur with patent ductus arteriosus if shunt reversal is directed entirely to the lower half of the body (Wood, 1958). Reduced compliance may add to the dyspnœea later in the disease if secondary changes develop in the interstitial tissues of the lung, but certainly compliances may be normal in the presence of dyspnœa in the earlier stages. The situation in mitral stenosis and left heart failure is different from that of primary pulmonary hypertension and the Eisenmenger syndrome in that there is pulmonary venous hypertension, venous and capillary mural thickening, extravascular fibrosis and œdema, each of which may impair the elasticity of the lung. Here the compliance is much reduced, even at levels of pressure insufficient to cause detectable pathological changes in the lungs or pulmonary vessels. According to Donald (1959) compliance is reduced abruptly as soon as the mean left atrial pressure exceeds $15 \mathrm{~mm}$. $\mathrm{Hg}$.

The evidence also indicates that an increased pulmonary blood flow does not of itself cause stiff lungs. Many patients with atrial septal defect with a large pulmonary: systemic flow ratio are without symptoms and can undertake strenuous activity without dyspnœa. This fact alone excludes any serious reduction of compliance in them. It is true that some cases of atrial septal defect without pulmonary hypertension do show a low compliance (our Cases 23 and 24; also Ayres et al., 1960), but this is exceptional. Our Case 21 provides a good example of normal compliance associated with a high pulmonary blood flow. Ventricular septal defect without pulmonary hypertension is also usually associated with normal compliance (Cases 12 and 16).

If it is agreed that neither pulmonary hypertension per se nor an increased pulmonary blood flow per se results in diminished compliance, what is the cause of the stiff lungs of hyperkinetic pulmonary hypertension? Three possibilities present themselves: (1) The characteristic chest deformity might be the cause rather than the result of stiff lungs. (2) Both chest deformity and low compliance might be the result of recurrent respiratory infection in childhood. (3) A combination of high pressure and high flow might stiffen the lungs when neither alone would do so. These possibilities will be considered in turn.

That this deformity is closely related to ventricular septal defect with hyperkinetic pulmonary hypertension is beyond question, but the relationship to ventricular septal defect might be embryological, and the hyperkinetic pulmonary hypertension coincidental, for the latter is far more commonly associated with ventricular septal defect than with any other form of congenital heart disease. However, the development of an identical type of thoracic deformity in cases of patent ductus (see clinical data of Anderson and Coles, 1955), aorto-pulmonary window, persistent truncus, transposition (Fig. 6), and common atrio-ventricular canal, when there is associated hyperkinetic pulmonary hypertension, but not otherwise, does not support an embryological relationship between the thoracic deformity and ventricular septal defect or a clinical relationship between the thoracic deformity and hyperkinetic pulmonary hypertension. Moreover, a similar deformity may also be 
seen in cases of cor triatriatum (Fig. 9) and congenital mitral stenosis, when the mechanical properties of the lung, particularly compliance, are impaired for a different reason. It is virtually certain, therefore, that the altered lung mechanics are the cause of the chest deformity rather than vice versa. This is readily understood when one observes the inspiratory lifting of the sternum and indrawing of the lower ribs that accompany dyspnœa in an infant with a large ventricular septal defect, pulmonary hypertension, and a rapidly increasing pulmonary blood flow as the pulmonary vascular resistance falls after birth.

The occasional findings of a similar chest deformity in individuals with Fallot's tetralogy or the Eisenmenger syndrome may mean that at one stage there was hyperkinetic pulmonary hypertension, and that the pulmonary blood flow has since been reduced, either by infundibular hypertrophy or pulmonary vascular occlusion. We have not enough evidence to be sure of this, but what we have is suggestive.

In the present study, all the patients with hyperkinetic pulmonary hypertension had a marked chest deformity except Case 1, in whom the antero-posterior diameter was only slightly increased. None of the patients with ventricular septal defect and normal pulmonary artery pressure, and none with secundum-type atrial septal defect, showed it. However, two patients with total anomalous pulmonary venous drainage had the same deformity in a mild degree. Both were boys of 15 years of age, with mean pulmonary artery pressures of 20 and $21 \mathrm{~mm}$. $\mathrm{Hg}$ and a pulmonary blood flow of $11 \mathrm{l} . / \mathrm{min}$. The mean P.A.P. in these cases was just below the arbitrary $25 \mathrm{~mm}$. Hg which we fixed for the lower limit of hyperkinetic pulmonary hypertension, and of course we do not know what it was in childhood. The frequency of pulmonary hypertension and chest deformity in total anomalous drainage is alluded to by Keith et al. (1958). The finding of normal lung stiffness in one of these cases does not deny impaired compliance in infancy, if the pulmonary artery pressure was then higher.

By the same token, however, it cannot be argued that the finding of stiff lungs in childhood or adolescence necessarily means that they were stiff in infancy: only actual measurement will settle this. Although proof is incomplete we feel that the evidence connecting the shape of the chest with the mechanical forces operating in the thorax is too strong to be rejected.

Lung Infections. Clinical impression has it that the incidence of lung infection in childhood is much greater in the presence of pulmonary hypertension of the hyperkinetic variety than in normal children. In a separate study this has been confirmed, and we have observed also that respiratory infection in children with Eisenmenger's syndrome is relatively rare. Two factors may explain this: the disturbance in mechanics discussed above, and the effect of an enlarged heart. In simple atrial septal defect, the heart is relatively small in infancy, since the pulmonary blood flow is not at first excessive. Likewise the heart is relatively small in the Eisenmenger syndome in which a high pulmonary vascular resistance prevents an increase in pulmonary blood flow. When there is a large shunt from left to right the heart is always enlarged, and in the hyperkinetic pulmonary hypertensive group both the large shunt and the large heart are established soon after birth. Edwards and Burchell (1960) have described the distorting effects of an enlarged heart on the infant tracheobronchial tree, particularly when the left atrium is enlarged. This is the case in V.S.D., where significant left atrial hypervolæmia and a slight rise in left atrial pressure are usual. In three of the cases of V.S.D. in the present series the left atrial pressure ranged between 9 and $15 \mathrm{~mm}$. $\mathrm{Hg}$ at rest.

It is difficult, therefore, to be sure whether pulmonary plethora or cardiac enlargement is chiefly responsible for the tendency to attacks of acute bronchitis, for these two factors are usually found together. Certainly the effect of infection may be important in determining pulmonary function in later life. Case 5 illustrates this well; until the age of eight years this girl suffered repeatedly with pneumonia, and pulmonary function tests at the age of seventeen showed gross disturbance of volumes, ventilation and diffusion. The compliance was $0.038 \mathrm{litre} / \mathrm{cm}$. Three other patients in our series with hyperkinetic pulmonary hypertension gave a history of pneumonia in early childhood, but their compliances at the time they were seen were not dissimilar to those found in the other cases with hyperkinetic pulmonary hypertension.

Recurrent bronchitis or bronchopneumonia in childhood in cases of uncomplicated atrial septal 
defect does not appear to give rise to thoracic deformity of the type described, and pulmonary function is usually normal subsequently. Again, there is no evidence that a bilaterally bulged thorax and poor compliance are less common in patients with hyperkinetic pulmonary hypertension who have escaped respiratory infection entirely. It is concluded that recurrent respiratory infection in infancy or early childhood is not responsible for the low compliance and characteristic thoracic deformity of hyperkinetic pulmonary hypertension, although it may be a contributory factor in some cases. The validity of this conclusion has been reaffirmed by the recent observation of a child with hyperkinetic pulmonary hypertension who showed the characteristic chest deformity at the age of two years without any evidence whatever of previous lung infection.

The Pulmonary Vasculature. Muscle exists in the walls of small pulmonary arteries in which the diameter lies between 100 and 1000 microns. The pathological changes in the pulmonary vessels associated with altered states of flow and pressure have been extensively studied (Edwards 1957; Heath and Edwards, 1958; Evans and Short, 1958). In atrial septal defect without pulmonary hypertension they are dilated to accommodate the increased flow, and the walls are thin and of low tension. In V.S.D. with increased flow and low pressure the situation is similar. In V.S.D. with hyperkinetic pulmonary hypertension the vessels have a large lumen to carry the increased flow, and a thick wall in view of the high pressure. In the Eisenmenger group the lumen is small since the flow is low, while the walls are thick and of high tension.

The pulmonary arteries and their branches are an integral part of the lung structure, so that expansion of the lung must be accompanied by elongation and torsion of these vessels. If the vessels possess any properties of elasticity or rigidity, these will manifest themselves in the overall mechanical characteristics of the lung. In so far as these properties vary from group to group as outlined in the previous paragraph, so will their effect on compliance vary. The question is, how much?

The force required to twist a tube of given length through a given angle, one end being fixed, varies directly with the fourth powers of the radius of inner and outer walls and with the coefficient of rigidity of the material composing the wall. A tube of large lumen with a wall that is both thick and relatively rigid will require a much greater force to distort it than one whose lumen is small or whose wall is thin or flaccid. The idea that the pulmonary vasculature forms an erectile scaffolding endowed with the properties of rigidity and compliance is by no means new, and may well be pertinent to the question at issue.

It seems to us that such considerations may play a significant role in determining the mechanical properties of the lungs under conditions of altered pulmonary blood flow and pressure, and thereby play a part in explaining some clinical facts and determining the natural history of the disease state present.

\section{SUMMARY}

That bilateral anterior bulging of the chest with indrawing of the lower ribs is closely related to hyperkinetic pulmonary hypertension is re-affirmed.

Measurement of compliance in a series of 34 selected cases representing varying combinations of pressure and flow in the pulmonary circulation suggests that the deformity is caused by stiff lungs.

Other conditions with low compliance in infancy and early childhood, such as cor triatriatum and congenital mitral stenosis, may have a similar thoracic deformity.

The low compliance of hyperkinetic pulmonary hypertension may well be a function of the vascular scaffolding of the lung, which in these circumstances is composed of thick walled vessels of large lumen in a unique combination. These vessels should in theory be particularly resistant to distortion.

Some of the cases from the National Heart Hospital were under the care of Dr. Aubrey Leatham, and we thank him for his permission to study them. Dr. Frank Prime of the Institute of Diseases of the Chest, Brompton Hospital, generously allowed the use of his facilities for pulmonary function testing and all this work was carried out in his laboratory. The lung volumes were measured by Miss Vivienne Scott. 


\section{REFERENCES}

Anderson, I. M., and Coles, H. M. T. (1955). Thorax, 10, 338.

Ayres, S. M., Kozam, R. L., and Lukas, D. S. (1960). Abstracts of 33rd Sci. Session, A.H.A.

Davies, H. (1959). Brit. J. Dis. Chest, 53, 151.

Donald, K. W. (1959). Progress in Cardiovascular Disease, 1, 298.

Dubois D., and Dubois, E. F. (1915). Arch. intern. Med., 15, 868.

Edwards, J. E. (1957). Circulation, 15, 164.

—- and Burchell, H. (1960). Dis. Chest, 38, 272.

Evans, W., and Short, D. S. (1958). Brit. Heart J., 20, 529.

Frank, N. R., Mead, J., Siebens, A. A., and Storey, C. F. (1956). J. appl. Physiol., 9, 38.

Heath, D., and Edwards, J. E. (1958). Circulation, 18, 533.

Keith, J. D., Rowe, R. D., and Vlad, P. (1958). Heart Disease in Infancy and Children. Macmillan, New York. Marshall, R. (1957). Clin. Sci., 16, 12.

McIlroy, M. B., and Apthorp, G. (1958). Brit. Heart J., 20, 397.

McMichael, J. (1939). Clin. Sci., 4, 167.

Pryor, W. W., Hickman, J. B., Page, E. B., and Siecker, H. O. (1955). Amer. J. Med., $19,149$.

- and Page, E. B. (1954). Amer. J. Med., 16, 606.

Saxton, G. A., Rabinowitz, M., Dexter, L., Haynes, F., and Walker, C. (1956). J. clin. Invest., $35,611$.

Wood, P. (1958). Brit. med. J., 2, 5099. 